\title{
Intravesical capsaicin for treatment of detrusor hyperreflexia
}

\author{
Clare J Fowler, R O Beck, Sue Gerrard, C D Betts, C G Fowler
}

\begin{abstract}
An intravesical instillation of $100 \mathrm{ml} 1$ or $2 \mathrm{mmol} / \mathrm{l}$ capsaicin has been used to treat detrusor hyperreflexia giving rise to intractable urinary incontinence in 12 patients with spinal cord disease and two other patients with detrusor overactivity of non-spinal origin. Nine patients, all of whom had spinal cord disease, showed some improvement in bladder function. The benefit was only shortlived and partial in four, but the remaining five achieved complete continence while performing intermittent self catheterisation. Urodynamic studies in these nine patients showed an increase in mean (SD) bladder capacity from 106 (57) to 302 (212) $\mathrm{ml}$ and $\mathrm{a}$ fall in the maximum detrusor pressure from 54 (20) to 36 (10) cm of water. There were no short term ill effects from the instillation and the improvement in bladder function lasted for between three weeks to six months, when in some patients it was repeated. The improvement in bladder behaviour shown in this study can be interpreted as showing that capsaicin sensitive afferents play an important part in the pathogenesis of detrusor hyperreflexia in spinal humans. Intravesical capsaicin seems a promising means of treating intractable detrusor hyperreflexia and studies with this substance may shed new light on other disorders of detrusor activity that cause incontinence.
\end{abstract}

$(\mathcal{F}$ Neurol Neurosurg Psychiatry 1994;57:169-173)

Department of UroNeurology, National Hospital for Neurology and Neurosurgery, Queen Square, London WC1N 3BG, UK Department of Urology, Royal London Hospital Trust, Whitechapel, London E1 1BB, UK

C J Fowler

R J Fowler

$S$ Gerrard

C D Betts

C G Fowler

Correspondence to:

Dr C J Fowler, Department

of Uro-Neurology, National

Hospital for Neurology and

Neurosurgery, Queen

Square, London WCIN

3BG, UK.

Received 11 March 1993

and in revised form

17 May 1993

Accepted 21 May 1993 afferent nerves that give rise to abnormal reflex detrusor contractions would have significant advantages over other means now available to treat neurogenic incontinence, especially if it were easy to administer and repeat and had a prolonged action.

Detrusor hyperreflexia can result either from loss of the normal inhibitory input from higher centres on to the pontine micturition centre or after a spinal lesion from interruption of the spinobulbospinal pathways that normally control physiological bladder behaviour. Animal models of chronic spinal cord disease have shown that after disruption of the connections between the pons and the sacral spinal cord a new segmental sacral reflex arc becomes functional. ${ }^{1}$ The afferent neurones of this emergent reflex in the cat are mostly unmyelinated $\mathrm{C}$ fibres whereas in the neurologically intact animal afferent neurones from the bladder are small myelinated $\mathrm{A} \delta$ fibres. ${ }^{2}$ Little is known of the neurological mechanism of bladder reflexes in spinally injured humans. ${ }^{1}$ Disconnection of the sacral cord from the pons results in detrusor areflexia that lasts for about six weeks before volume determined bladder reflex emptying becomes established. A speculative hypothesis is that this change in detrusor behaviour results from synaptic reorganisation and possibly new nerve growth forming the neurological basis of an emerging reflex arc.

Pharmacological experiments show that in many species there is a large group of fibres innervating the bladder that are capsaicin sensitive. ${ }^{3-6}$ These are mostly unmyelinated fibres in the cat ${ }^{1}$ and rat. $^{7}$ They are silent under physiological conditions but may be activated by bacterial or chemical irritants in the bladder ${ }^{8}$ giving rise to symptoms of cystitis. It is probably these same fibres that emerge active and serve as the afferent arc for detrusor hyperreflexia in spinally injured animals. ${ }^{1}$

Capsaicin activates a vanilloid receptor on the cell membrane of sensitive primary sensory neurones ${ }^{9}$ causing an increase in cation permeability and leading to membrane depolarisation. Activation of the vanilloid receptor produces a biphasic response. The immediate effect is stimulatory with transmission of sensory impulses from the periphery to the central nervous system sensed as a painful irritation and a peripheral release from the receptor terminals of neuropeptides including substance $P$ and CGRP. After exposure to high concentrations of capsaicin, afferent $C$ fibres may show long lasting functional 
changes, with many unmyelinated fibres having morphological evidence of structural damage. The degree of neurotoxicity that follows exposure to systemic treatment with capsaicin depends on the age of the animal: high doses given subcutaneously to newborn rats result in a $50 \%$ or greater reduction in unmyelinated fibres ${ }^{10}$ whereas when given to adult animals there is not so much fibre loss. ${ }^{11}$ Applied topically to peripheral nerve, capsaicin has an extensive selective neurotoxic effect on unmyelinated fibres irrespective of the animal's age and causes axonal loss of unmyelinated fibres ${ }^{12} 13$ and depletion of neuropeptides. ${ }^{14}$ Little is known about the long term neurotoxic effects of capsaicin when it is applied directly to nerve terminals.

Capsaicin has been enjoyed as a constituent of the human diet for thousands of years and no long term side effects have been recognised from ingestion of large quantities of it. Capsaicin applied directly to the eyes, nose, mouth, and throat is intensely painfula property of the substance now being exploited by riot control police. ${ }^{15}$ Low doses of capsaicin have been injected intravenously into human volunteers to study its effect on respiratory and cardiovascular reflexes ${ }^{16}$ and it is now being used to examine the cough reflex in patients with various types of lung disease. ${ }^{17}$ Skin ointments containing capsaicin are being used to treat postherpetic neuralgia ${ }^{18}$ and painful diabetic neuropathy. Its potential application in the treatment of other painful disorders has recently been reviewed. ${ }^{19}$ The use of capsaicin in the human bladder has so far been limited to treatment of painful bladder disorders, with concentrations of $0 \cdot 1-10 \mu \mathrm{m} .^{20}$

Systemic administration of capsaicin to neonatal rats results in urinary retention and loss of those bladder afferents immunoreactive for substance $P .{ }^{21}$ When capsaicinsensitive afferents were shown to be present in the human bladder ${ }^{20}$ the use of intravesical capsaicin to lessen detrusor hyperreflexia in humans was suggested (CA Maggi, personal communication). The lessening of detrusor hyperreflexia in spinal cats after a subcutaneous injection of capsaicin ${ }^{1}$ made bladder instillation with this substance the logical step when faced by patients with neurogenic incontinence resistant to currently available medical treatments and unsuitable for surgery.

The early results of this study were the subject of a preliminary report. ${ }^{22}$

\section{Patients}

All patients gave informed consent after a clear explanation that capsaicin was being obtained as a chemical, not a medicine and had no certification for use in humans. A medicine exemption certification was obtained for the use of capsaicin for intravesical administration from the Medicines Advisory Committee and the project was approved by the Joint Ethics Committee of the National Hospital for Neurology and Neurosurgery and Institute of Neurology.

The table gives details of patients. Twelve patients had spinal cord disease: eight had multiple sclerosis with varying degrees of disability, one had tropical spastic paraparesis with moderate lower limb paraparesis but could walk with sticks, one had had an arteriovenous fistula of the spinal cord and was confined to a wheel chair, one had had an episode of transverse myelitis three years earlier, and one patient had congenital spina bifida. All patients with multiple sclerosis and the one with tropical spastic paraparesis had urodynamically verified hyperreflexia with phasic detrusor contractions and incontinence induced at a mean volume of 106 (57) $\mathrm{ml}$. The remaining three patients $(2,4$ and 5$)$ had a steady rise in detrusor pressure on filling with poor compliance calculated at 3.7, $2 \cdot 6$, and $1.3 \mathrm{ml} / \mathrm{cm}$ water, respectively.

Table Clinical details of 14 patients treated with intravesical capsaicin showing the clinical extent of their incontinence and cystometric findings before and after treatment

\begin{tabular}{|c|c|c|c|c|c|c|c|c|c|}
\hline \multirow{3}{*}{$\begin{array}{l}\text { Patient } \\
\text { no }\end{array}$} & \multirow{3}{*}{$\begin{array}{l}\text { Age } \\
(y)\end{array}$} & \multirow[b]{3}{*}{ Diagnosis } & \multirow[b]{3}{*}{ Disability } & \multicolumn{2}{|l|}{ Extent of clinical incontinence } & \multirow{2}{*}{\multicolumn{2}{|c|}{ Capacity $(\mathrm{ml})$}} & \multirow{2}{*}{\multicolumn{2}{|c|}{$\begin{array}{l}\text { Detrusor pressure at } \\
\text { capacity }\left(\mathrm{cm} \mathrm{H}_{2} \mathrm{O}\right)\end{array}$}} \\
\hline & & & & Before & & & & & \\
\hline & & & & treatment & treatment & Before & After & Before & After \\
\hline 1 & 68 & $\begin{array}{l}\text { Neurologically } \\
\text { normal }\end{array}$ & $\begin{array}{l}\text { Walking } \\
\text { normally }\end{array}$ & Pads & No improvement & 20 & 20 & 65 & 60 \\
\hline 2 & 27 & Vegetative state & Bed bound & $\begin{array}{l}\text { Bypassing and extruding } \\
\text { catheter }\end{array}$ & $\begin{array}{l}\text { No extrusion for } 3 \\
\text { weeks }\end{array}$ & $\mathbf{N} / \mathbf{P}$ & $\mathbf{N} / \mathbf{P}$ & & \\
\hline 3 & 22 & Spina bifida & Chair bound & Pads & No improvement & 130 & 100 & 35 & 60 \\
\hline 4 & 57 & $\begin{array}{l}\text { Cord AV } \\
\text { malformation }\end{array}$ & Chair bound & Indwelling catheter & No improvement & 220 & 220 & 85 & 80 \\
\hline 5 & 14 & $\begin{array}{l}\text { Transverse } \\
\text { myelitis }\end{array}$ & $\begin{array}{l}\text { Walking } \\
\text { abnormally }\end{array}$ & Pads & Mostly dry & 80 & 70 & 60 & 50 \\
\hline $\begin{array}{l}6 \\
7\end{array}$ & $\begin{array}{l}37 \\
38\end{array}$ & $\begin{array}{l}\text { Multiple sclerosis } \\
\text { Multiple sclerosis }\end{array}$ & $\begin{array}{l}\text { Chair bound } \\
\text { Bed bound }\end{array}$ & $\begin{array}{l}\text { Indwelling catheter } \\
\text { Bypassing and extruding } \\
\text { catheter }\end{array}$ & $\begin{array}{l}\text { No improvement } \\
\text { Less bypassing for } 8 \\
\text { weeks }\end{array}$ & $\begin{array}{r}100 \\
30\end{array}$ & $\begin{array}{r}300 \\
30\end{array}$ & $\begin{array}{l}40 \\
30\end{array}$ & $\begin{array}{l}30 \\
30\end{array}$ \\
\hline 8 & 57 & Multiple sclerosis & Bed bound & $\begin{array}{l}\text { Bypassing and extruding } \\
\text { catheter }\end{array}$ & $\begin{array}{l}\text { No bypassing for } 8 \\
\text { weeks }\end{array}$ & 140 & $\mathbf{N} / \mathbf{P}$ & 70 & \\
\hline 9 & 67 & Multiple sclerosis & Bed bound & Bypassing catheter & No improvement & 150 & $\mathbf{N} / \mathbf{P}$ & 95 & \\
\hline 10 & 54 & $\begin{array}{l}\text { Tropical spastic } \\
\text { paraparesis }\end{array}$ & $\begin{array}{l}\text { Walking with } \\
\text { sticks }\end{array}$ & Pads & Continent with ISC & 195 & 400 & 50 & 32 \\
\hline 11 & 40 & Multiple sclerosis & $\begin{array}{l}\text { Walking with } \\
\text { sticks }\end{array}$ & Pads & Continent with ISC & 130 & 250 & 95 & 45 \\
\hline 12 & 45 & Multiple sclerosis & $\begin{array}{l}\text { Walking with } \\
\text { sticks }\end{array}$ & Urosheath and bag & Continent with ISC & 110 & 560 & 60 & 30 \\
\hline 13 & 57 & Multiple sclerosis & $\begin{array}{l}\text { Walking with } \\
\text { sticks }\end{array}$ & Urosheath and bag & Continent with ISC & 150 & 260 & 45 & 20 \\
\hline 14 & 56 & Multiple sclerosis & $\begin{array}{l}\text { Walking with } \\
\text { frame }\end{array}$ & Indwelling catheter & Continent with ISC & 50 & 550 & 40 & 28 \\
\hline
\end{tabular}

ISC $=$ intermittent self catheterisation; $\mathrm{N} / \mathrm{P}=$ not performed. 
Intravesical capsaicin was also used in two other patients, one of whom was in a persistent vegetative state with an indwelling catheter after severe cerebral anoxia. The other was the only patient in this series who was neurologically normal and the cause of her disabling incontinence due to involuntary detrusor contractions is unknown.

The table shows the clinical extent of incontinence in all patients before capsaicin instillation and the results of urodynamic studies.

\section{Methods}

Preliminary studies in one of the patients (14) carried out in 1990 showed that low concentrations of capsaicin $(0 \cdot 1-10 \mu \mathrm{m} / \mathrm{l})$ had no effect on improving bladder capacity or lessening hyperreflexia. From May 1991 onwards, $100 \mathrm{ml}$ of either $1 \mathrm{mmol} / 1(0.3 \mathrm{~g} / \mathrm{l})$ or $2 \mathrm{mmol} / 1$ solution of capsaicin dissolved in $30 \%$ alcohol in saline were used. This was introduced into the bladder with a balloon catheter to minimise the risk of leakage into the urethra. The instillation was left in the bladder for 30 minutes.

For the first five patients the instillation procedure was carried out in the operating theatre with full cardiovascular monitoring and in the presence of an anaesthetist to give analgesia or sedation if required. All patients, except one who had lost bladder sensation, reported immediate suprapubic burning that persisted with severe intensity for between 5-10 minutes, but no patient requested analgesia. When it became clear that the instillation was adequately tolerated in alert subjects, subsequent patients were treated in the uro-neurology laboratory with an anaesthetist available. No medical intervention was ever required either for management of pain or cardiovascular support.

Two bed-bound patients with multiple sclerosis and catheter-induced urethral incompetence had a bladder neck suspension procedure carried out under general anaesthetic at the same time as the instillation to prevent leakage of the capsaicin into the urethra.

Blood was taken for measurement of alcohol concentrations over the period of the instillation and up to four hours later.

All except one patient had standard medium fill ( $50 \mathrm{ml} /$ minute) subtraction cystometry studies before and after the instillation. Whenever possible cystometry was carried out immediately before the capsaicin instillation and intravesical pressure measurements were continued during the instillation. Urodynamic studies were repeated four to eight weeks after the capsaicin instillation in 11 patients but not in those who were bedbound (patients 2, 8 and 9).

\section{Results}

IMMEDIATE EFFECTS AND SHORT TERM RESULTS (FIRST 14 DAYS)

When the procedure was carried out in the operating theatre the patients were connected to a $\mathrm{PO}_{2}$ oximeter and ECG monitor. No significant alteration in cardiovascular state occurred during or after the procedure. Although most patients reported immediate suprapubic pain, lasting with intensity for 5-10 minutes and then diminishing, none reported symptoms that could have been related to systemic effects of capsaicin. The rise in blood alcohol after the instillation never exceeded $3 \mathrm{mmol} / \mathrm{l}$, indicating that there was little diffusion of the alcohol through the bladder wall. Patients who had had the procedure once and were returning for repeated treatments denied undue apprehension of discomfort and it seemed that subsequent treatments were less uncomfortable than the first. Patients were well enough to go home immediately afterwards.

When urodynamic studies were performed during the instillation a sharp rise in detrusor pressure was immediately seen, often followed by a series of phasic contractions. A full report of aspects of this phenomenon will be the subject of a separate paper.

All patients reported an initial deterioration of their symptoms with either worsening incontinence or catheter bypassing for a period that varied between 24 hours to 14 days followed then by clinical improvement or a return to their previous state. Patients who had the instillation carried out more than once seemed to have the same pattern of response on each occasion.

\section{LONG TERM RESULTS (TWO WEEKS TO SIX MONTHS)}

The table summarises the urodynamic changes and clinical response after intravesical capsaicin. An improvement in some aspect of bladder behaviour was seen in nine of the 14 patients. In five the improvement was highly satisfactory so that these patients who had formerly required the long term use of a continence appliance or pads, became continent between intermittent self catheterisations. The bladder capacity in these five patients increased from 127 to $404 \mathrm{ml}$ (fig 1). Hyperreflexic contractions were reduced with a fall in detrusor pressure from 58 to $31 \mathrm{~mm}$ $\mathrm{H}_{2} \mathrm{O}$ and lessening of the degree of urgency. In another four patients the improvement was less impressive both in terms of degree and duration. Two of these patients had procedures for bladder neck suspension carried out at the time of capsaicin instillation because they had such severe dilatation of the urethra after catheter extrusions that leakage of capsaicin into the urethra during the instillation procedure would otherwise have been inevitable. It is possible that the surgical procedure alone improved continence although one patient continued to be incontinent for two weeks after the procedure and only then stopped leaking around the catheter for the next eight weeks before the problem returned. An improvement in clinical continence was achieved in one other patient (5) in whom medium fill $(50 \mathrm{ml} / \mathrm{min})$ cystometry showed no change although filling at a slow rate $(10 \mathrm{ml} / \mathrm{min})$ after the treatment showed a 
Figure 1 Changes in bladder capacity in the 11 patients in whom data were available, before and after capsaicin instillation.

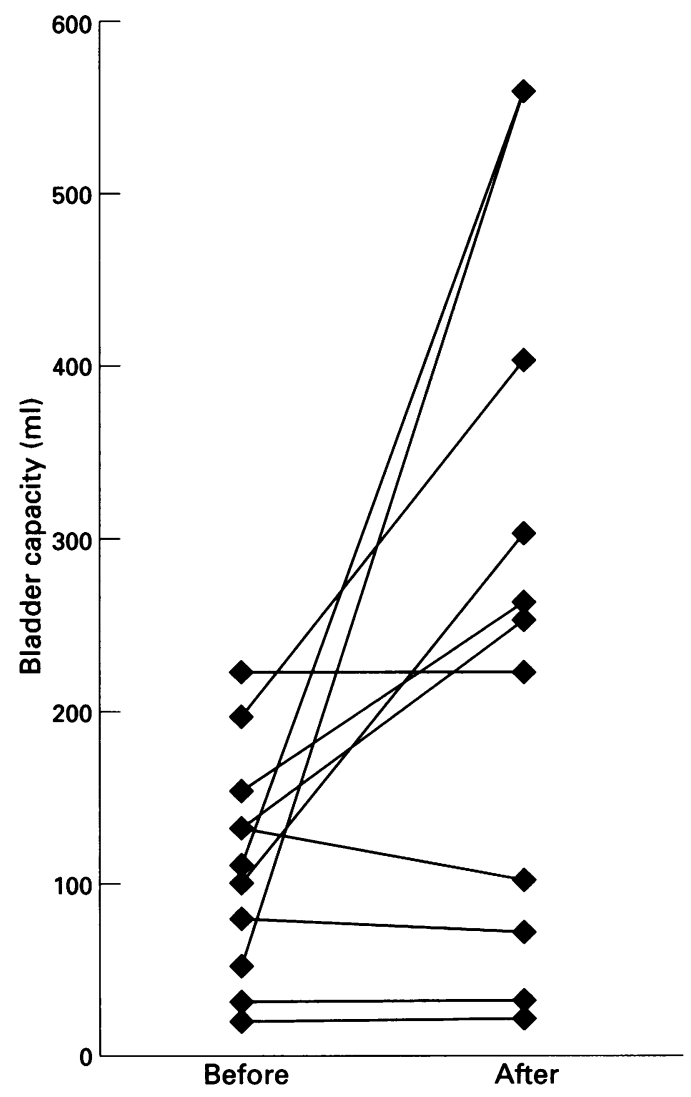

greatly improved capacity.

The remaining four patients showed neither clinical nor urodynamic evidence of improvement after capsaicin instillation. This group included the patient who was neurologically normal and one with severe multiple sclerosis who was incontinent with severe flexor leg spasms. Also in the non-responding group were two patients ( 3 and 4) whose urodynamic studies had shown poor compliance rather than phasic detrusor hyperreflexia.

\section{DURATION OF ACTION AND REPEATED} INSTILLATIONS

Figure 2 shows the timing of the intravesical instillations in each patient. Three patients have had the instillation repeated at intervals of between four and nine months when they have felt a return of their urinary urgency and reduction in their postmicturition residuals as assessed by intermittent self catheterisation. Urodynamic studies carried out at this stage show that there had been a reduction in blad-

Figure 2 Time in month since capsaicin instillation. Patient numbers as used in the table are given on the ordinate. Each square indicates an episode of intravesical capsaicin. A line indicates the duration of improved bladder function. der capacity and return of hyperreflexia, but never so severe as before the first capsaicin instillation. The instillation has not been repeated in those who showed neither clinical nor urodynamic change.

\section{Discussion}

This is the first human study to show that capsaicin-sensitive afferents are important in the pathophysiological mechanisms which cause the detrusor hyperreflexia that follows a spinal lesion. Although clinical continence was achieved in only five out of the 14 patients treated with intravesical capsaicin, there was evidence of either short-lived clinical improvement in four others and urodynamic evidence of an increased capacity in one further patient. Those who did not respond included two patients with low bladder compliance rather than phasic detrusor contractions, a patient with severe flexor leg spasms, and the patient who was neurologically normal. The pathogenesis of low bladder compliance is unknown but these findings suggest that it is different from that which causes phasic detrusor hyperreflexia. It is not surprising that the neurologically normal patient did not respond and the failure of response of the patient with extreme disability and multiple sclerosis may lie in the severity of the abnormality in that case.

A complete block of the emergent reflex that drives volume-determined detrusor contractions would result in an areflexic bladder, as occurs in neonatal rats treated with capsaicin. ${ }^{21}$ The bladder would then require to be emptied by intermittent self catheterisation; a technique already practised by many patients with spinal cord disease. This state was not reached in any of the patients in the series described here although conditions approaching it were achieved in the five patients with the best responses. The severity of urinary incontinence of a spinally compromised patient depends on a combination of factors that include a reduction in bladder capacity and the magnitude of hyperreflexic detrusor contractions. In patient 6 there was an increase in bladder capacity but persisting clinical continence was not achieved as she was still incontinent with low pressure rises.

The duration of benefit after intravesical capsaicin is variable and ranged from months to weeks (fig 2). There is a clear suggestion that the effectiveness of intravesical capsaicin in improving continence is related to the patient's overall neurological state, best illustrated by the fact that clinical continence was achieved only in those whose neurological disability was less severe and who were still able to walk (patients $1-5$, table). The benefit in those with the most severe neurological deficit was short lived and difficulties with mobility and transport in such patients made repeated treatments, with the expectation of only temporary relief of symptoms, impractical in a pilot study. This aspect of the relation between responsiveness and neurological deficit deserves further study because if it 
were possible to measure the neural depletion responsible for symptomatic improvement, and in the severely disabled this was only partial, a treatment regimen with either higher concentrations or more frequent instillations would be rational.

Topical capsaicin applied to the skin results in a reduction of the flare response and raising of heat pain thresholds lasting several weeks. ${ }^{23}$ The prolonged effect seen in some of these patients implies that there has been a degree of axonal loss. The rich plexus of suburothelial nerves in the bladder of humans are thought to be sensory ${ }^{24}$ and substance $\mathbf{P}$ and other neuropeptides known to occur in association with sensory nerves have been identified in the human bladder. ${ }^{25}$ It is proposed that in the circumstances of the instillation procedure described here, high concentrations of capsaicin reached the nerve terminals themselves. Future studies will include an immunocytochemical examination of the suburothelial sensory nerves before and after topical application of capsaicin to assess the extent of substance $P$ depletion and to test whether clinical response can be correlated to measurable neuronal loss.

Little is known about the effect of alcohol in the human bladder. Two patients have been reported in whom undiluted Bonney's blue (a 1:1 mixture of brilliant green and crystal violet dissolved in $90 \%$ ethanol) was mistakenly instilled intravesically, resulting in chemical cystitis and in the long term, a reduced bladder capacity. ${ }^{26}$ The possibility that the changes in bladder behaviour reported here might be due to the $30 \%$ alcohol in saline solution has not been eliminated. A study is in progress to examine this with patients who have been shown to respond to capsaicin, waiting until the benefit of the last capsaicin instillation has worn off and then instilling the solution of alcohol in saline alone. A blinded study will not be possible because the pungent effects of capsaicin are so obvious to both the administrator and recipient.

The promising results of intravesical capsaicin treatment reported here were predicted from the extensive animal studies that have shown the presence of capsaicin-sensitive afferents in the bladder of many species ${ }^{45}$ and the work of de Groat and colleagues ${ }^{1}$ who have shown the change in nature of the afferent limb of the reflex arc for detrusor hyperreflexia in chronic spinal animals. Its use in other conditions where unwanted detrusor contractions cause incontinence, such as detrusor instability in the elderly, might shed light on the neurobiology of such disorders. This study suggests a new method of treatment for patients with intractable neurogenic incontinence and confirms that capsaicin sensory afferents exist in the human bladder and are functionally significant in detrusor hyperreflexia secondary to spinal disease.
We thank consultants of the National Hospital for Neurology and Neurosurgery, Queen Square for referring patients and the Joint Ethics Committee of the Hospital and Institute of Neurology for their advice. The assistance given by the Department of Anaesthesia and the Pharmacy of the National Hospital is gratefully acknowledged. Discussions with D Chet de Groat, Dr Bruce Lynn, and Dr Carlo Maggi have been invaluable. Equipment used for urodynamic studies was purchased by a grant from the Multiple Sclerosis Society of Great Britain and Northern Ireland.

de Groat WC, Kawatani T, Hisamitsu T, et al. Mechanisms underlying the recovery of urinary bladder function following spinal cord injury. $\mathcal{F}$ Auton Nerv Syst 1990;30:S71-8.

2 de Groat WC. Central neural control of the lower urinary tract. In: Bock G, Whelan J, eds. Neurobiology of incontinence (Ciba Foundation Symposium 151). Chester: Wiley 1990:27-56.

3 Szolcsanyi J. Capsaicin-sensitive chemoceptive neural system with dual sensory-efferent function. In: Chahl LA, Szolcsanyi J, Lembeck F, eds. Antidromic vasodilation and neurogenic inflammation. Budapest: Akademiai and neurogenic in

4 Jancso G, Maggi CA. Distribution of capsaicin-sensitive urinary bladder afferents in the rat spinal cord. Brain Res 1987;418:371-6.

5 Maggi CA, Santicioli P, Borsini F, et al. The role of capsaicin-sensitive innervation of the rat urinary bladder in the activation of the micturition reflex. Naunyn Schmiedebergs Arch Pharmacol 1986;322:276-83.

$6 \mathrm{Maggi}$ CA. The role of peptides in the regulation of the micturition reflex: an update. Gen Pharmacol 1991; 22:1-24.

7 Maggi CA, Lippe ITH, Giuliani S, et al. Topical versus systemic capsaicin desensitization: specific and unspecific effects as indicated by modification of reflex specific effects as indicated by modification of
micturition in rats. Neuroscience 1989;31:745-56.

8 McMahon SB, Koltzenburg M. Novel classes of nociceptors: beyond Sherrington. Trends Neurosci 1990;13 199-201

9 Szallasi A., Blumberg PM. Resiniferatoxin and its analogs provide novel insight into the pharmacology of the vanilloid (capsaicin) receptor. Life Sci 1991;47 1399-408.

10 Scadding JW. The permanent anatomical effects of neonatal capsaicin on somatosensory nerves. I Ana 1980;131:473-84.

11 Jancso G, Kiraly E, Joo F, Such G, Nagy A. Selective degeneration by capsaicin of a subpopulation of primary sensory neurons in the adult rat. Neurosci Lett 1985; 59:209-14.

12 Lynn B. The immediate and long-term effects of applying capsaicin to cutaneous nerves. Acta Physiol Hung 1986; 69:287-94.

13 Pini A, Baranowski R, Lynn B. Long-term reduction in the number of $\mathrm{C}$-fibre nociceptors following capsaicin the number of C-fibre nociceptors following capsaicin treatment of a cutaneo

14 Jessel TM, Iversen LL, Cuello AC. Capsaicin-induced depletion of substance $\mathbf{P}$ from primary neurones. Brain Res 1978;152:183-8.

15 Park P. Police cool it with cayenne pepper. New Sci 1992 18/3:23.

16 Winning AJ, Hamilton RD, Shea SA, Guz A. Respiratory and cardiovascular effects of central and periphera intravenous injections of capsaicin in man: evidence for pulmonary chemosensitivity. Clin Sci 1986;71:519-26.

17 Fuller RW. The human pharmacology of capsaicin. Arch Int Pharmacodyn Ther 1990;303:147-56.

18 Bernstein JE, Bickers DR, Dahl MV, Roshal JY. Treatment of chronic postherpetic neuralgia with topical capsaicin. $₹ \mathrm{Am} \mathrm{Acad} \mathrm{Dermatol} \mathrm{1987;17:93-6.}$

19 Lynn B. Capsaicin: actions on nociceptive C-fibres and therapeutic potential. Pain 1990;41:61-9.

20 Maggi CA, Barbanti G, Santicioli P, et al. Cysometric evidence that capsaicin-sensitive nerves modulate the afferent branch of micturition reflex in humans. F Urol 1989b;142:150-4.

21 Sharkey KA, Williams RG, Schultzberg M, Dockray GJ. Sensory substance $P$-innervation of the urinary bladder: possible site of action of capsaicin in causing urin retention in rats. Neuroscience 1983;10:861-8.

22 Fowler CJ, Jewkes D, McDonald WI, Lynn B, de Groat WC. Intravesical capsaicin for neurogenic bladder dysfunction (letter). Lancet 1992;339:1239.

23 Carpenter SE, Lynn B. Vascular and sensory responses of human skin to mild injury after topical treatment with capsacin. Br f Pharmacol 1981;73:755-8.

24 Dixon JS, Gilpin CJ. Presumptive sensory axons of the human urinary bladder. A fine ultrastructural study. human urinary bladder.

25 Edyvane KA, Marshall VR. Neuropeptides in the human urinary tract. Neurourol Urodynamics, 1990;9:346-7.

26 Christmas TJ, Chapple CR, Payne SDW, et al. Bonney's blue cystitis: a warning. Br $\mathcal{f}$ Urol 1989;63:281-3. 